\title{
Stability of African swine fever virus in soil and options to mitigate the potential transmission risk
}

\author{
Jolene Carlson ${ }^{1}$, Melina Fischer ${ }^{2}$, Laura Zani², Michael Eschbaumer ${ }^{3}$, Walter Fuchs ${ }^{4}$, \\ Thomas Mettenleiter ${ }^{5}$, Martin Beer ${ }^{5,6}$, and Sandra Blome ${ }^{2}$ \\ ${ }^{1}$ Friedrich-Loeffler-Institut Bundesforschungsinstitut fur Tiergesundheit \\ ${ }^{2}$ Friedrich-Loeffler-Institute \\ ${ }^{3}$ Institute of Diagnostic Virology, Friedrich-Loeffler-Institut, Federal Research Institute for \\ Animal Health \\ ${ }^{4}$ Friedrich-Loeffler-Institut \\ ${ }^{5}$ Friedrich-Loeffler-Institut \\ ${ }^{6}$ Influenza $_{N} R L$
}

July 23, 2020

\begin{abstract}
Understanding African swine fever virus (ASFV) transmission in a population is essential for strategies to minimize virus spread during an outbreak. ASFV can survive for extended periods of time in animal products, carcasses, and the environment. Recent studies have shown that wild boar demonstrate interest in carcasses at an advanced stage of decay and in the soil where the remains of wild boar once were. While ASFV nucleic acids have been found in the environment around infected farms, data on the survival of the virus in soil are scarce. We investigated different soil matrices spiked with ASFV-positive blood from infected wild boar to see if ASFV can remain viable in the soil beneath infected carcasses. Moreover, we tried different mitigation strategies that could be used in affected regions. As expected, ASFV genome detection was reliably possible over the full range of sampling days. Soil $\mathrm{pH}$, structure, and ambient temperature played a significant role for the stability of infectious ASFV. Infectious ASFV was demonstrated in specimens originating from sterile sand for at least three weeks, and from ordinary beach sand for up to two weeks. In yard soil, infectious ASFV was demonstrated for one week, and in soil from a swampy area for three days. Virus was not recovered from two acidic forest soils. All risk mitigation experiments with citric acid or calcium hydroxide resulted in complete inactivation in our experimental setup. In conclusion, stability of infectious ASFV is almost non-existent in forest soils but rather high in sandy soils. However, given the high variability, treatment of carcass collection points with disinfectants should be considered for additional risk reduction. In this respect, biocidal nature and occupational safety have to be considered.
\end{abstract}

\section{Original Article}

\section{Stability of African swine fever virus in soil and options to mitigate the potential transmission risk}

Running title: ASFV stability and inactivation in soil

Jolene Carlson11Present affiliation: Ceva Animal Health, Greifswald, Germany, Melina Fischer, Laura Zani, Michael Eschbaumer, Walter Fuchs, Thomas Mettenleiter, Martin Beer, Sandra Blome

Friedrich-Loeffler-Institut, Suedufer 10, 17493 Greifswald - Insel Riems, Germany

Corresponding author: 
PD Dr. Sandra Blome

Friedrich-Loeffler-Institut

Institute of Diagnostic Virology

Südufer 10

17493 Greifswald - Insel Riems

Phone: +49-38351-71144; Fax: +49-38351-71226, Email: sandra.blome@fli.de

\section{Summary}

Understanding African swine fever virus (ASFV) transmission in a population is essential for strategies to minimize virus spread during an outbreak. ASFV can survive for extended periods of time in animal products, carcasses, and the environment. Recent studies have shown that wild boar demonstrate interest in carcasses at an advanced stage of decay and in the soil where the remains of wild boar once were. While ASFV nucleic acids have been found in the environment around infected farms, data on the survival of the virus in soil are scarce. We investigated different soil matrices spiked with ASFV-positive blood from infected wild boar to see if ASFV can remain viable in the soil beneath infected carcasses. Moreover, we tried different mitigation strategies that could be used in affected regions.

As expected, ASFV genome detection was reliably possible over the full range of sampling days. Soil $\mathrm{pH}$, structure, and ambient temperature played a significant role for the stability of infectious ASFV. Infectious ASFV was demonstrated in specimens originating from sterile sand for at least three weeks, and from ordinary beach sand for up to two weeks. In yard soil, infectious ASFV was demonstrated for one week, and in soil from a swampy area for three days. Virus was not recovered from two acidic forest soils. All risk mitigation experiments with citric acid or calcium hydroxide resulted in complete inactivation in our experimental setup. In conclusion, stability of infectious ASFV is almost non-existent in forest soils but rather high in sandy soils. However, given the high variability, treatment of carcass collection points with disinfectants should be considered for additional risk reduction. In this respect, biocidal nature and occupational safety have to be considered.

Keywords : African swine fever virus, stability, soil, disinfection, risk mitigation

\section{Introduction}

In the last decade, African swine fever (ASF) has reached an unprecedented geographical spread affecting wild boar and domestic swine in large parts of Europe and Asia, as well as several areas in Africa (Dixon et al., 2020). The notifiable disease of suids can be accompanied by signs of a viral hemorrhagic fever in domestic pigs and Eurasian wild boar (Sanchez-Vizcaino et al., 2015). The virus is transmitted directly between infected swine and wild boar by the oro-nasal route, indirectly by ingestion of contaminated meat. It can also be transmitted by competent vectors, i.e. soft ticks of the genus Ornithodoros. They play an important role in Africa, but only in a few areas outside this continent (Costard et al., 2013). Despite its limited host range and non-existent zoonotic potential, the socio-economic impact is high and many stakeholders are involved (Gallardo et al., 2015).

During the first years of the current epidemic that started in Georgia in 2007, infections were mainly seen among pig farms with generally low biosecurity, and with incidental spill over to the wild boar population. In the EU, however, the infection survived in the wild boar population independently from outbreaks in domestic pigs (Chenais et al., 2019).

For the transmission among wild boar, carcasses and the contaminated habitat seem to play a crucial role, together with humans as long-distance spreaders (Chenais et al., 2019).

So far, there are only a few cases in the current European outbreak where the disease was completely eradicated from a country's wild boar population. One case is the Czech Republic, where the control measures 
successfully applied there are used as guide for ongoing efforts elsewhere (Dixon et al., 2020). The other case is Belgium which is very close to becoming free of ASFV as no new wild boar cases have been detected (fasfc.be, 2020). Both countries followed EU policy to keep the virus concentrated in one zone as much as possible.

An integral part of the control strategy is to search for and remove carcasses as a potential virus source. In this context, the question was raised whether the soil under a removed wild boar carcass should be also removed or treated to prevent virus transmission to other wild boar rooting in the contaminated soil. It was shown that viral genome can be detected in such soil (Arvo Viltrop and Imbi Nurmoja, personal communication) and in order to minimize the transmission risk, simple physical measures such as loosening the soil, but also the application of disinfectants were intensively debated. Commercial disinfectants as well as lime products, i.e. quicklime and limewater (an aqueous solution of calcium hydroxide), were considered as possible options.

Consequently, our experiments began simply to establish a protocol to isolate ASFV from soil samples but evolved over time as we obtained more data. We set out to determine basic values of the stability of ASFV in soil matrices and how infectivity could be reduced.

\section{Material and Methods}

Experimental design and amendments to the protocols over time

After learning that the soil underneath a carcass can be positive for ASFV genome, we started a pilot experiment based on existing protocols for the analysis of soil samples. During these experiments, it was essential to continuously improve our methods to increase the robustness and sensitivity of the detection of infectious ASFV. In detail, we accomplished this by increasing the virus inoculation volumes and then by increasing the sensitivity and robustness of virus isolation detection methods. Besides, for arid soil types it was necessary to adjust the volume of medium used to recover the virus from the soil.

During the study, it turned out that primary swine macrophages were too sensitive to toxic effects from the soil matrices. Therefore, we switched to a permanent wild boar lung (WSL) cell line. In contrast to the non-dividing macrophages, these cells can divide quickly and seem to be more resistant to matrix effects. Using this optimized cell culture technique, we had the benefit of using ASFV "Kenya1033" genotype IX in which the gene encoding the viral CD2 homologue was replaced with that of a red fluorescent reporter protein (Hubner et al., 2018). With the WSL cells and the marker virus, the detection of viral replication was accelerated to 5-7 days after titration.

\section{Collection and analysis of soil}

Half a kilogram of soil was collected from each of five locations in Mecklenburg-Western Pommerania, Germany (see Figure 1). The soil types chosen (yard soil, two kinds of forest soil, swamp mud and beach sand) were based on locations where wild boar are commonly found. In addition, a bag of commercial potting soil was purchased to have a more controlled matrix with neutral $\mathrm{pH}$, compared to the acidic forest soil samples collected (see Table S1 in the supplemental material), and sterile sea sand was obtained from a lab supplier (Carl Roth, Karlsruhe, Germany). The collected soils were analysed by an agricultural laboratory in Rostock, Germany (Landwirtschaftliche Untersuchungs- und Forschungsanstalt, LUFA) (see Table 2 in the supplemental material).

Description of inoculums prepared for soil spiking.

In experiments 1-3, whole blood was collected from wild boar experimentally infected with ASFV "Armenia08". These animal trials were previously conducted for pathogenesis studies. The blood was mixed for 15-20 minutes with glass beads to remove fibrin. The blood was then stored at $-80^{\circ} \mathrm{C}$ until use. Since experiments were completed at different time points, stocks for spiking the soil matrices had different titers, but differed no more than one $\log$ in considered volumes. Infected blood from experiment 1 had a titer of 
$7.25 \log _{10} 50 \%$ hemadsorbing doses $\left(\mathrm{HAD}_{50}\right)$ per $\mathrm{mL}$, blood from experiment 2 had a titer of $6.00 \log _{10}$ $\mathrm{HAD}_{50} / \mathrm{mL}$ and blood from experiment 3 had a titer of $7.00 \log _{10} \mathrm{HAD}_{50} / \mathrm{mL}$.

ASFV-Kenya1033 $\triangle$ CD2vdsRed was derived from ASFV-Kenya1033 as described by Hübner et al. (2018) by substitution of the CD2v ORF (EP402R) from codon 77 to the translational stop codon (386) by a dsRed expression cassette.

Experiment 1: Recovery of ASFV from yard soil on macrophages, a first pilot experiment

In a pilot experiment, $5 \mathrm{~g}$ of yard soil were spiked with $400 \mu \mathrm{L}$ of infectious blood at a titer of 7.25 $\log _{10} \mathrm{HAD}_{50} / \mathrm{mL}$ and stored at $4^{\circ} \mathrm{C}$ or $25^{\circ} \mathrm{C}$. In this study, blood and soil were tested at time points 0 , 3, 6, 24, 48, and $72 \mathrm{~h}$. First, $5 \mathrm{ml}$ of RPMI-1640 cell culture medium (Thermo Fisher Scientific, Schwerte, Germany) with 10\% fetal bovine serum (FBS) and 2\% antibiotics (Gibco Penicillin-Streptomycin mix, 10000 U/ml; Thermo Fisher Scientific) was added to the inoculated soil. Then the soil was agitated in the media by vortexing for 45 seconds (see Figure 2 for all steps). Next, soil and media were sonicated for 45 seconds at $4^{\circ} \mathrm{C}$ with the settings: duty cycle $40 \%$, output 3.5 with a Branson Sonifier 450 (Heinemann Ultraschallund Labortechnik; Schwäbisch Gmünd, Germany). After sonication, the soil suspension was centrifuged for 30 minutes at $2,500 \mathrm{x} \mathrm{g}$ at $4^{\circ} \mathrm{C}$. The supernatant was poured over a coffee filter, pushed through a $0.45 \mu \mathrm{m}$ syringe filter (Millex Filter Units; Merck Millipore Ltd., Tullagreen, Ireland) and the filtrate was stored at $-80^{\circ} \mathrm{C}$ prior to titration.

Experiment 2: Recovery from sterile sand, beach sand, swamp mud, and forest soil on macrophages

The collected soils were tested along with two controls: blood-only and blood mixed with 6 grams of sterile sea sand. All soils and controls were spiked with $1.2 \mathrm{~mL}$ of ASFV-positive blood with a titer of $6.00 \log _{10}$ $\mathrm{HAD}_{50} / \mathrm{mL}$ and three replicates per condition. The forest soils were extremely dry, so $12 \mathrm{ml}$ of media were added to all samples for virus isolation. We continued experiment 2 and subsequent experiments at room temperature $\left(25^{\circ} \mathrm{C}\right)$, since we had not seen big differences between soil stored at $4{ }^{\circ} \mathrm{C}$ or $25^{\circ} \mathrm{C}$ in experiment 1. We limited our testing to 14 days in experiment 2 as it seemed unlikely that live virus would be detected beyond one week. In addition to the protocol described in experiment 1, we also used a dedicated kit for DNA extraction from soil (DNeasy PowerSoil; Qiagen, Hilden, Germany) from 0.25 grams of all matrices and time points.

Experiment 3: Recovery of live virus from beach sand on macrophages.

Experiment 2 was repeated with beach sand and $2 \mathrm{~mL}$ of ASFV-positive blood with a titer of 7.25 $\log _{10} \mathrm{HAD}_{50} / \mathrm{mL}$ at room temperature, due to inconclusive virus isolation results (data not shown). A larger volume of blood was used to increase the chances for virus detection in this matrix that previously gave mixed results. In the repeated experiment, blood-only and sterile sand were included as controls. Every experimental condition was completed with 3 replicates.

Experiment 4: Recovery of live virus with WSL-adapted CD2v-deleted ASFV Kenya and disinfection treatments

A virus stock was prepared by mixing $160 \mathrm{~mL}$ of supernatant from WSL cells infected with WSL-adapted CD2v-deleted ASFV Kenya virus with $500 \mathrm{~mL}$ of defibrinated whole blood from a domestic swine resulting in a final ASFV titer of $6.00 \log _{10} \mathrm{TCID}_{50} / \mathrm{mL}$.

A $2 \mathrm{~mL}$ volume of the spiked blood was used to inoculate $6 \mathrm{~g}$ beach sand and commercial potting soil at room temperature. A blood-only tube and sterile sand were again included as controls. The protocol was followed as described above, with the omission of sonication as the samples were too numerous to sonicate in the 3 -hour intervals between the first three collections. All sample conditions were completed with 3 replicates. Samples were treated with $3.5 \%$ and $7.5 \%$ calcium hydroxide or $3.5 \%$ and $7.5 \%$ citric acid (by weight of soil). After each soil matrix was inoculated, the powdered disinfectants were added, vortexed and incubated for 1 or 3 hours at room temperature.

Virus isolation on porcine macrophages and on WSL cells 
Virus isolation and titration were completed with macrophages derived from peripheral blood mononuclear cells (PBMCs). Blood was collected from healthy domestic pigs in heparin tubes. The whole blood was diluted 1:1 in phosphate-buffered saline (PBS), $35 \mathrm{~mL}$ of diluted blood was overlaid on $12 \mathrm{~mL}$ of Pancoll (PAN-Biotech, Aidenbach, Germany) and spun at $730 \mathrm{x}$ g for 40 minutes at $20^{\circ} \mathrm{C}$ with slow acceleration and no brake. The PBMCs were collected and washed twice in PBS and passed over $70 \mu \mathrm{m}$ nylon strainers to remove any fatty debris. For blind passages, $5 \times 10^{6}$ PBMCs were seeded into each well of 24 -well Corning Primaria plates (Corning, Durham, USA). Titrations were completed with $7.5 \times 10^{6}$ cells per mL in 96-well

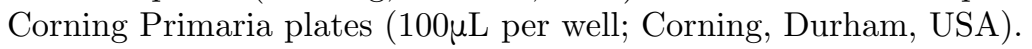

PBMCs were cultured in RPMI-1640 medium supplemented with $10 \%$ fetal bovine serum (FBS), $2 \%$ antibiotics, $75 \mu \mathrm{L}$ mercaptoethanol (Merck, Darmstadt, Germany) and $2.5 \mathrm{ng} / \mathrm{mL}$ granulocyte macrophage colony-stimulating factor (GM-CSF; Biomol, Hamburg, Germany) for the first day, then with $5 \mathrm{ng} / \mathrm{mL}$ GM-CSF from the second day after a media change.

A volume of $300 \mu \mathrm{L}$ soil supernatant was inoculated per well on a 24 -well plate with $700 \mu \mathrm{L}$ of media. The following day, the cells were washed with media once and the supernatant in each well was replaced with $1 \mathrm{~mL}$ of fresh media. The cells were cultivated for 5 days prior to freezing at $-80^{\circ} \mathrm{C}$ for subsequent virus titration.

Wild boar lung cells (WSL) were cultivated in Iscove's Modified Dulbecco's Medium with Ham's F-12 Nutrient Mix (Thermo Fisher Scientific), 10\% FBS and 2\% antibiotics.

For virus isolation, WSL cells were seeded the day before with $10^{6}$ cells per well in a 24 -well tissue culture plate (Corning, Durham, USA). A volume of $300 \mu \mathrm{L}$ soil supernatant was inoculated on a 24 -well plate with $700 \mu \mathrm{L}$ of media, and subsequently changed the next day and replaced with $1 \mathrm{~mL}$ of fresh media. The cells were cultivated for 5 days prior to freezing at $-80^{\circ} \mathrm{C}$ for subsequent virus titration. Titrations were completed with $4 \times 10^{5}$ WSL cells per mL using $100 \mu \mathrm{L}$ per well in a 96-well tissue culture plate (Corning, Durham, USA) seeded one day prior to inoculation. Cells were inoculated with $100 \mu \mathrm{L}$ of virus isolation supernatant from one round of virus amplification in the 24-well plate described above. Titrations were completed in ten-fold dilutions starting with $10^{-1}$ to $10^{-8}$ and calculated by the Spearman-Kärber method $\log _{10} 50 \%$ end point dilution with a limit of detection of $1.75 \mathrm{TCID}_{50} / \mathrm{mL}$.

Virus detection via real-time PCR

Prior to real-time PCR analysis, nucleic acids from soil samples were extracted using the DNeasy PowerSoil kit (Qiagen, Hilden, Germany) according to the manufacturer's recommendations. Subsequently, nucleic acids were analyzed using a published real-time PCR assay targeting the ASFV p72 gene (Tignon et al., 2011) in combination with an internal control based on beta actin (Toussaint et al., 2007) on a CFX96 real-time cycler (Bio-Rad Laboratories, Hercules, USA). PCR was performed with the QuantiTect Multiplex PCR Kit (Qiagen, Hilden, Germany) in a total volume of $25 \mu \mathrm{L}$. Using a dilution series of an ASFV DNA standard, the genome copies in the respective samples were determined. For generation of the ASFV standard, DNA from an ASFV "Armenia08" PBMC culture supernatant was extracted using the QIAamp Viral RNA Mini Kit (Qiagen, Hilden, Germany) according to the manufacturer's recommendations. Subsequently, the DNA concentration was determined by spectrophotometry using a Nanodrop 2000c (Thermo Fisher Scientific) and the exact number of DNA molecules was calculated with an online tool (http://www.molbiol.edu.ru/eng/scripts/01 07.html).

\section{Results}

\section{Recovery of ASFV from yard soil on macrophages (Experiment 1)}

In this pilot experiment yard soil was spiked with blood from ASFV infected wild boar and stored for four weeks at $25^{\circ} \mathrm{C}$ or $4^{\circ} \mathrm{C}$. A blood-only control was carried along under the same conditions.

Regarding the blood-only control stored at $4^{\circ} \mathrm{C}$, a high variability of the determined virus titers was observed during the first 48 hours (Figure 3 ). Titers of the 3 biological replicates ranged between $3.75 \log _{10} \mathrm{HAD}_{50} / \mathrm{mL}$ 
and $7.00 \log _{10} \mathrm{HAD}_{50} / \mathrm{mL}$ after an incubation time of six hours at $4^{\circ} \mathrm{C}$. Such a variation did not reoccur at later time points or in the blood-only control stored at $25^{\circ} \mathrm{C}$. In general, virus titers in pure blood decreased clearly after two weeks storage at either temperature. However, the blood-only controls $\left(4^{\circ} \mathrm{C}\right.$ and $\left.25^{\circ} \mathrm{C}\right)$ remained infectious over the entire observation period.

Virus titers in yard soil spiked with infectious blood and stored at $4{ }^{\circ} \mathrm{C}$ or $25^{\circ} \mathrm{C}$ generally decreased within the first 72 hours (Figure 3). In contaminated yard soil stored at $25^{\circ} \mathrm{C}$ no infectious virus was detectable after 72 hours. After one week, however, a high variability between the biological replicates was observed in yard soil at both storage temperatures, with virus titers up to $5.50 \log _{10} \mathrm{HAD}_{50} / \mathrm{mL}$ at $25^{\circ} \mathrm{C}$. Hence, we found that ASFV remained infectious in yard soil ( $\mathrm{pH}$ 6.7) for up to 7 days at both temperatures. After two weeks, contaminated yard soil was clearly negative for infectious virus until the end of the study.

Irrespective of the storage temperature, ASFV genome copy numbers were constant over time in the bloodonly control and in yard soil samples.

Virus recovery from sterile sand, beach sand, swamp mud, and forest soil on macrophages (Experiments 2 and 3)

Three different soil types (beach sand, swamp mud, forest soil) were inoculated with blood from an ASFV infected wild boar and stored at room temperature for up to three weeks. A blood-only control and sterile sand mixed with infectious blood were carried along as process controls under the same conditions. In these experiments, virus titers in pure blood remained stable over the three-week storage period at room temperature and no decline in virus titers was observed after two weeks (Figure 4). Virus titers in the sterile sand control, however, decreased constantly over time. Nevertheless, both process controls (blood-only and sterile sand) contained infectious virus over the entire observation period.

In beach sand, high virus titers between $5.50 \log _{10} \mathrm{HAD}_{50} / \mathrm{mL}$ and $6.50 \log _{10} \mathrm{HAD}_{50} / \mathrm{mL}$ were observed directly after application of infectious blood $(0 \mathrm{~h})$, but no infectious virus could be detected from three days until the end of the experiment (Figure 4). In contrast, no infectious virus could be recovered from either forest soil specimen ( $\mathrm{pH} 4.1$ and 3.2), even immediately after the application of infectious blood. In swamp mud (pH 5.1), however, low residual titers were found directly after the addition of infectious blood. From day three until the end of the observation period, no infectious virus was recovered from swamp mud.

ASFV genome, however, was detectable in all investigated soil types/matrices and no distinct decline in copy numbers was recorded over the entire observation period.

Recovery of infectious WSL-adapted CD2v-deleted ASFV Kenya and disinfection treatments (Experiment 4)

To evaluate the improved cell culture technique using WSL cells (see Figure 5), beach sand or yard soil were inoculated with blood spiked with WSL-adapted CD2v-deleted ASFV Kenya and stored at room temperature for three weeks. Furthermore, the different matrices were treated with two different disinfectants for one or three hours. A blood-only control and sterile sand mixed with infectious ASFV-blood were used as process controls under the same conditions.

Virus titers in the blood-only and sterile sand controls remained constant over the entire observation period, no decrease in virus titer was observed (Figure 6). Thus, untreated blood or sterile sand were infectious for the entire test interval of 3 weeks. Inoculated beach sand and yard soil however, displayed a steady decline in virus titer over time (during the first week). After one week a high variability between the biological replicates was observed in the beach sand. Moreover, in both soil types, no infectious virus could be detected after two weeks storage at room temperature.

Regardless of the matrix/soil type (sterile sand, beach sand, yard soil), no infectious virus could be recovered after a one-hour disinfectant treatment (calcium hydroxide or citric acid) at either concentration (Figure 5). ASFV in pure blood was also fully inactivated after treatment with either disinfectant for one hour at room temperature. In all tested matrices, ASFV genome copy numbers were relatively constant over time. In disinfectant-treated samples, slightly fewer genome copies were detected (Figure 6). 


\section{Discussion}

African swine fever is no longer an exotic disease and has established self-sustaining, complicated transmission cycles in European wild boar populations. Slow but constant local spread is observed (data from the Animal Disease Notification System, visited online May $\left.8^{\text {th }}, 2020\right)$. This was rather unexpected as historical experience did not indicate that wild boar could sustain an endemic infection cycle (Laddomada et al., 1994). Field observations and experimental studies indicate a high lethality (Blome et al., 2012, Gabriel et al., 2011) and low contagiosity, especially in the initial phase of an ASF outbreak among wild boar. The low level of contagiosity requires a rethinking and an adapted approach to control ASF in the wild boar population (Depner et al., 2016a, Depner et al., 2016b). Evidence suggests that ASF in a feral pig population tends to behave more like a long-term (rather stationary) habitat-bound disease with no tendency to spread rapidly. It is mainly infectious cadavers, combined with the high tenacity of the ASF virus and the low contagiosity, that can contain the disease within a region (Depner et al., 2016b). ASFV-contaminated soil rooted by wild boar is one of the habitat factors that could play a role in transmission. Probst et al. (2017) reported that wild boar show interest in the soil where carcasses have been found previously, with wildlife cameras documenting animals rooting in soil even when only bones remained. Furthermore, Estonian colleagues and others have demonstrated viral genome in these soils (Viltrop and Nurmoja, personal communication)(Zani et al., 2020).

In our study we tried to create a data set for a risk assessment of the role of contaminated soil in ASFV transmission and possible mitigation measures.

We demonstrate that virus stability depends on the soil type, $\mathrm{pH}$, organic material percentage, and to a lesser extent, on ambient temperature. While contaminated sand retains infectivity for weeks, virus stability is very low in acidic forest soils. Intermediate times were found in swamp mud and yard soil. Within the limits of our experimental setup, and assuming that the animal is an even more sensitive detection system, we cannot rule out a persistence of infectivity for at least a couple of weeks. The residual infectivity was within the range that was shown to be infectious when orally applied to susceptible animals (McVicar, 1984, Pietschmann et al., 2015). These results contradict to a certain extent previously published studies (MazurPanasiuk and Wozniakowski, 2020), where water, soil and leaf litter inactivated ASFV quickly. In this study Mazur-Panasiuk and Wozniakowski (2020) were able to re-isolate ASFV from soil and leaf litter immediately after adding culture supernatant to the matrix, but even a short 3-day incubation caused complete loss of virus infectivity independent of temperature conditions. This is in line with our results from swamp mud but not from yard soil or sand, where much longer periods of infectivity were observed. In contrast, reisolation immediately after adding the contaminant to forest soil was impossible in our hands. Thus, virus inactivation seems to occur after short contact with the matrix e.g. due to the acidic conditions in both forest soil specimens ( $\mathrm{pH} 4.1$ and 3.2$)$.

Risk mitigation could involve the use of disinfectants despite the obvious limitation that decontamination of soils in fields and forests, which are very different in structure, consistency and composition, is generally difficult and the organic matter in body fluids impairs disinfection (Weber et al., 1999). We used citric acid and calcium hydroxide in our study, which both have proven efficiency against ASFV (Turner and Williams, 1999, Krug et al., 2012), the former with known inhibition by blood (Krug et al., 2018). It must be noted that in the past, lime products were used in the control of classical swine fever in wild boar, e.g. in Germany. It is assumed that they not only have a disinfectant effect but also repel wild boar. Furthermore, these products were well accepted by the hunters. The application of lime was therefore included in the official recommendation of the German government for the use of disinfectants in an epizootic (Blome et al., 2020). Despite the above information, it can be questioned whether the application of a basic chemical to acidic soils in the wild boar habitat is appropriate. ASFV is quite reliably inactivated at a $\mathrm{pH}$ of below 4 (EFSA, , 2009). Therefore, acidic disinfectants could be more useful and here, citric acid was our candidate.

In our study, ASFV was inactivated after $1 \mathrm{~h}$ of disinfectant treatment. In spiked beach sand and commercial potting soil not treated with disinfectant, ASFV was fully inactivated after 2 weeks. However, untreated blood or sterile sand were infectious for the entire test interval of 3 weeks with consistent results from virus isolation 
(macrophages) and titration on WSL cells.

In conclusion, ASFV stability is very low in forest soils but rather high in sandy soils. Given the high variability of wild boar habitats and unforeseen effects of the decay matrix, treatment of carcass locations with disinfectants should be considered when setting up control measures. The powder format of the used chemicals could be beneficial and practical. Nevertheless, regulations on the use of biocides and occupational safety have to be considered. Off-label use of commercial products could be an alternative. In this context, disinfectants based on potassium peroxymonosulfate (Trifectant, Virkon S) were recently shown to inactivate ASFV on porous surfaces (Gabbert et al., 2020) but had problems with blood under certain circumstances (Krug et al., 2018). Removal of ASFV-positive carcasses is of utmost importance and remains a critical control measure as live virus may remain infectious in certain soil matrices for weeks. These studies establish useful protocols to isolate ASFV from soil matrices, while providing insight to potential management options useful in the field to mitigate transmission.

\section{Acknowledgements}

The authors would like to thank all technicians (Anja Landmesser, Holger Freese and Ulrike Kleinert) involved in this study for their excellent work. This publication is partly based upon work from COST Action 15116 ASF-STOP supported by the European Cooperation in Science and Technology and was partially funded by the FLI ASF research network. We thank our colleagues from the Estonian Veterinary and Food Laboratory, Tartu, Estonia for the inspiration to begin this project.

\section{Ethical approval}

The animal experiments were performed in accordance with the EU Directive 2010/63/EC and German law. They were approved by the competent authority (Landesamt für Landwirtschaft, Lebensmittelsicherheit und Fischerei Mecklenburg-Vorpommern) under reference number 7221.3-2-011/19.

\section{Conflicts of interest statement}

The authors declare no conflicts of interest.

\section{Data availability statement}

The data that support the findings of this study are available from the corresponding author upon reasonable request.

\section{References}

Accessed July 13, 2020 https://www.fasfc.be/outbreaks-african-swine-fever

2009: EFSA Scientific Report on ASF.

Blome, S., C. Gabriel, K. Dietze, A. Breithaupt and M. Beer, 2012: High virulence of African swine fever virus caucasus isolate in European wild boars of all ages. Emerg Infect Dis, 18, 708.

Blome, S., I. Michels and C. Menge, 2020: Disinfection procedures for the different animal diseases : African swine fever [Desinfektionsverfahren bei den einzelnen Tierseuchen : Afrikanische Schweinepest] Recommendations of the Friedrich-Loeffler-Institut on means and procedures for carrying out disinfection required by animal health legislation [Empfehlungen des Friedrich-Loeffler-Instituts über Mittel und Verfahren für die Durchführung einer tierseuchenrechtlich vorgeschriebenen Desinfektion] . Friedrich-Loeffler-Institut, Greifswald - Insel Riems and Jena.

Chenais, E., K. Depner, V. Guberti, K. Dietze, A. Viltrop and K. Stahl, 2019: Epidemiological considerations on African swine fever in Europe 2014-2018. Porcine Health Manag, 5, 6.

Costard, S., L. Mur, J. Lubroth, J. M. Sanchez-Vizcaino and D. U. Pfeiffer, 2013: Epidemiology of African swine fever virus. Virus Res, 173, 191-197. 
Depner, D., C. Staubach, C. Probst, A. Globig, S. Blome, K. Dietze, S.-L. C. and F. Conraths, 2016a: African Swine fever - epidemiological considerations and consequences for disease control. Tierärztliche Umschau, Heft 3/2016, 72-78.

Depner, K., S. Blome, C. Staubach, C. Probst, A. Globig, K. Dietze, C. Sauter-Louis and F. Conraths, 2016b: African swine fever - a habitat-borne disease often of low contagiosity [Die Afrikanische Schweinepest - eine Habitatseuche mit häufig niedriger Kontagiosität]. Der Praktische Tierarztin, 97, 536-544.

Dixon, L. K., K. Stahl, F. Jori, L. Vial and D. U. Pfeiffer, 2020: African Swine Fever Epidemiology and Control. Annual review of animal biosciences, 8, 221-246.

Gabbert, L. R., J. G. Neilan and M. Rasmussen, 2020: Recovery and Chemical Disinfection of Foot-andMouth Disease and African Swine Fever Viruses from Porous Concrete Surfaces. J Appl Microbiol .

Gabriel, C., S. Blome, A. Malogolovkin, S. Parilov, D. Kolbasov, J. P. Teifke and M. Beer, 2011: Characterization of african Swine Fever virus caucasus isolate in European wild boars. Emerg Infect Dis, 17, $2342-2345$.

Gallardo, M. C., A. T. Reoyo, J. Fernandez-Pinero, I. Iglesias, M. J. Munoz and M. L. Arias, 2015: African swine fever: a global view of the current challenge. Porcine health management, 1, 21.

Hubner, A., B. Petersen, G. M. Keil, H. Niemann, T. C. Mettenleiter and W. Fuchs, 2018: Efficient inhibition of African swine fever virus replication by CRISPR/Cas9 targeting of the viral p30 gene (CP204L).Scientific reports, 8, 1449.

Krug, Larson, E. AC and R. LL., 2012: Disinfection of foot-and-mouth disease and African swine fever viruses with citric acid and sodium hypochlorite on birch wood carriers. 156, 96-101.

Krug, P. W., T. Davis, C. O'Brien, M. LaRocco and L. L. Rodriguez, 2018: Disinfection of transboundary animal disease viruses on surfaces used in pork packing plants. Veterinary microbiology, 219, 219-225.

Laddomada, A., C. Patta, A. Oggiano, A. Caccia, A. Ruiu, P. Cossu and A. Firinu, 1994: Epidemiology of classical swine fever in Sardinia: a serological survey of wild boar and comparison with African swine fever. Vet Rec, 134, 183-187.

Mazur-Panasiuk, N. and G. Wozniakowski, 2020: Natural inactivation of African swine fever virus in tissues: Influence of temperature and environmental conditions on virus survival. Veterinary microbiology, 242, 108609 .

McVicar, J. W., 1984: Quantitative aspects of the transmission of African swine fever. American journal of veterinary research, 45, 1535-1541.

Pietschmann, J., C. Guinat, M. Beer, V. Pronin, K. Tauscher, A. Petrov, G. Keil and S. Blome, 2015: Course and transmission characteristics of oral low-dose infection of domestic pigs and European wild boar with a Caucasian African swine fever virus isolate. Archives of virology, 160, 1657-1667.

Probst, C., A. Globig, B. Knoll, F. J. Conraths and K. Depner, 2017: Behaviour of free ranging wild boar towards their dead fellows: potential implications for the transmission of African swine fever.R Soc Open Sci, 4, 170054 .

Sanchez-Vizcaino, J. M., L. Mur, J. C. Gomez-Villamandos and L. Carrasco, 2015: An Update on the Epidemiology and Pathology of African Swine Fever. J Comp Pathol, 152, 9-21.

Tignon, M., C. Gallardo, C. Iscaro, E. Hutet, Y. Van der Stede, D. Kolbasov, G. M. De Mia, M. F. Le Potier, R. P. Bishop, M. Arias and F. Koenen, 2011: Development and inter-laboratory validation study of an improved new real-time PCR assay with internal control for detection and laboratory diagnosis of African swine fever virus. Journal of virological methods, 178, 161-170. 
Toussaint, J. F., C. Sailleau, E. Breard, S. Zientara and K. De Clercq, 2007: Bluetongue virus detection by two real-time RT-qPCRs targeting two different genomic segments. J Virol Methods, 140, 115-123.

Turner and Williams, 1999: Laboratory-scale inactivation of African swine fever virus and swine vesicular disease virus in pig slurry. $J$ Appl Microbiol .

Weber, D. J., S. L. Barbee, M. D. Sobsey and W. A. Rutala, 1999: The effect of blood on the antiviral activity of sodium hypochlorite, a phenolic, and a quaternary ammonium compound. Infection control and hospital epidemiology, 20, 821-827.

Zani, L., M. Masiulis, P. Busauskas, K. Dietze, G. Pridotkas, A. Globig, S. Blome, T. Mettenleiter, K. Depner and B. Karveliene, 2020: African swine fever virus survival in buried wild boar carcasses. Transboundary and emerging diseases .

\section{Figure headings}

Figure 1: Areas where soil was collected in northern Germany. Sources of yard soil, swamp mud, beach sand, and two forest soils are shown.

Figure 2: Downstream protocol for processing of soil samples for virus isolation and qPCR. Pictures show sample after media and soil matrix has been sonicated and centrifuged for 30 minutes at $2,500 \mathrm{x} \mathrm{g}$ at $4^{\circ} \mathrm{C}$.

Figure 3: Infectious wild boar blood $\left(7.25 \log _{10} \mathrm{HAD}_{50} / \mathrm{mL}\right.$ of ASFV Armenia08) and yard soil spiked with $400 \mu \mathrm{L}$ of it was stored at $25^{\circ} \mathrm{C}$ or $4^{\circ} \mathrm{C}$. ASFV genome copies per $\mathrm{mL}$ are depicted in black and virus titer is shown in red. Experiments were completed in triplicates and each circle represents each individual replicate.

Figure 4: (A) Different soil types spiked with $1.2 \mathrm{~mL}$ infectious blood $\left(6.0 \log _{10} \mathrm{HAD}_{50} / \mathrm{ml}\right.$ of ASFV Armenia08) and stored at room temperature. Genome copies are depicted in black and virus titer is shown in red. (B) Beach sand and sterile sand were inoculated with $2 \mathrm{~mL}$ of infectious blood and also incubated at room temperature. Blood only samples served as controls in both experiments. ASFV genome copies are depicted in black and virus titers are shown in red.

Figure 5: Cytopathic effect and simple ASFV titration readout with WSL cells infected with ASFV Kenya $\Delta$ CD2v-dsRed.

Figure 6: Different soil types were spiked with $2 \mathrm{ml}$ of spiked blood $(6.0 \log 10 \mathrm{HAD} 50 / \mathrm{mL}$ of ASFV Kenya $\Delta \mathrm{CD} 2 \mathrm{v}$-dsRed) and stored at room temperature for indicated times. ASFV genome copies (A) and virus titers on WSL cells (B) in untreated or disinfectant-treated matrices are shown.
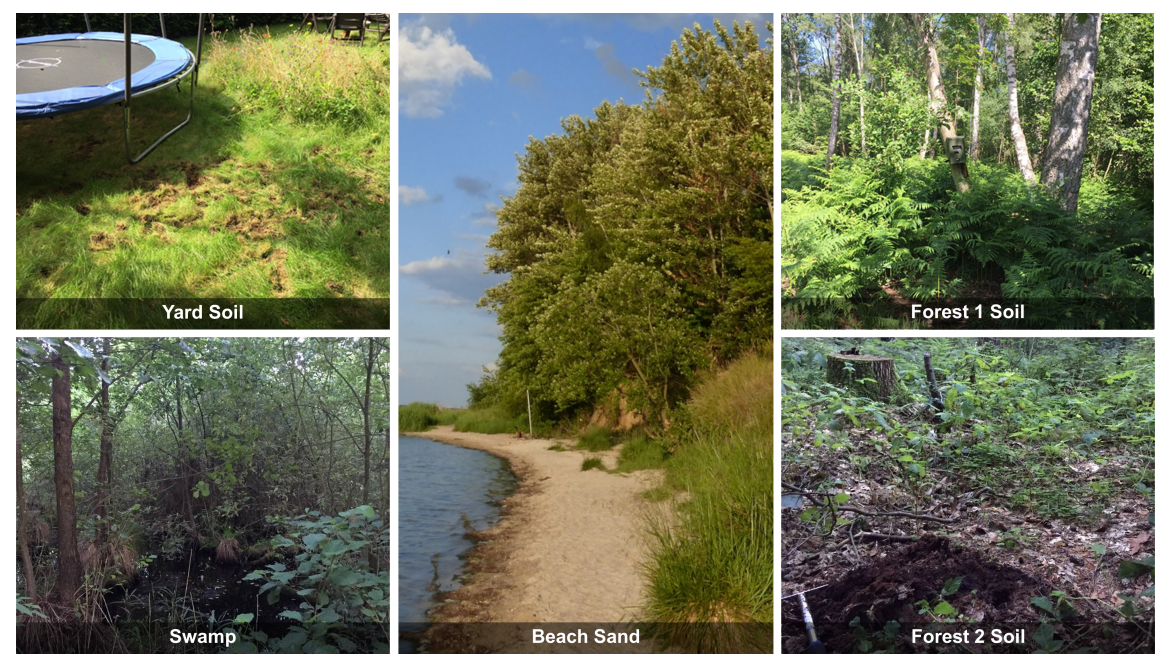

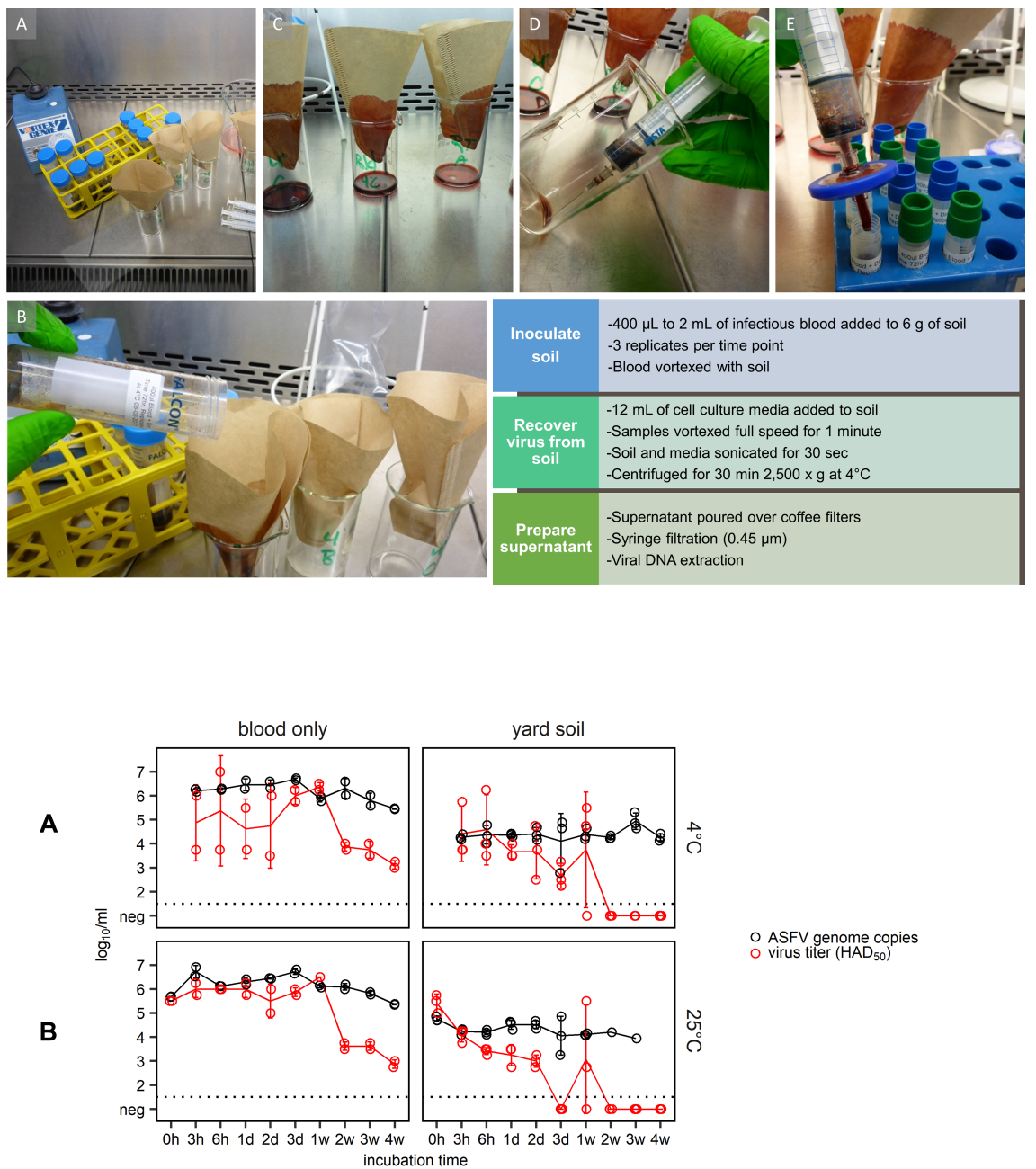

O ASFV genome copies
O virus titer ( $\left(\mathrm{HAD}_{50}\right)$

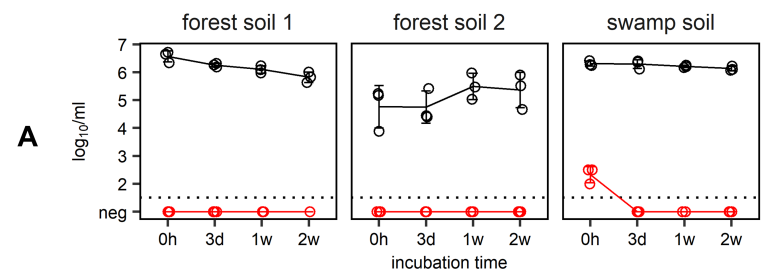

O ASFV genome copies
O virus titer (HAD $\left(H D_{50}\right)$
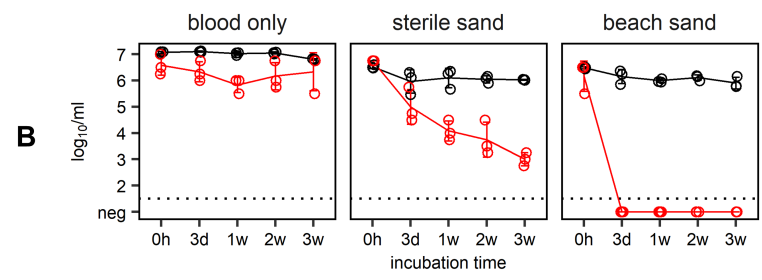

O ASFV genome copies
O virus titer ( $\left(H A D_{50}\right)$ 


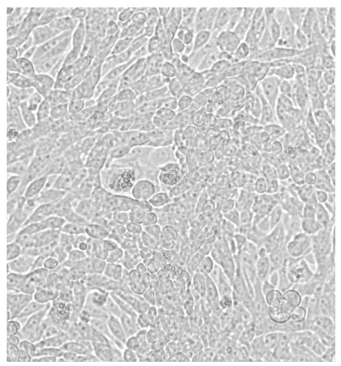

Negative WSL Cells

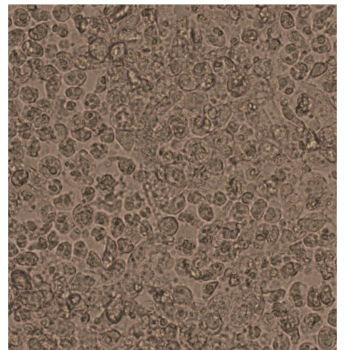

ASFV Kenya $\triangle$ CD2v-dsRed Infected WSL Cells

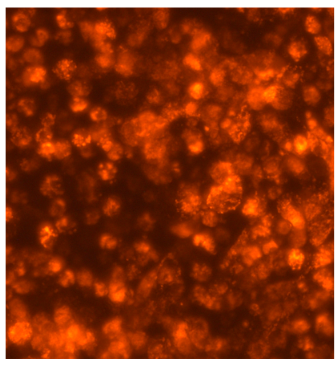

ASFV Kenya $\triangle$ CD2v-dsRed Infected WSL Cells
A
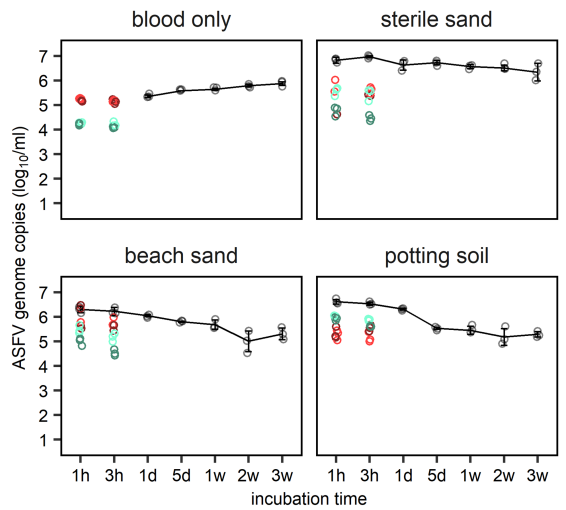

incubation time

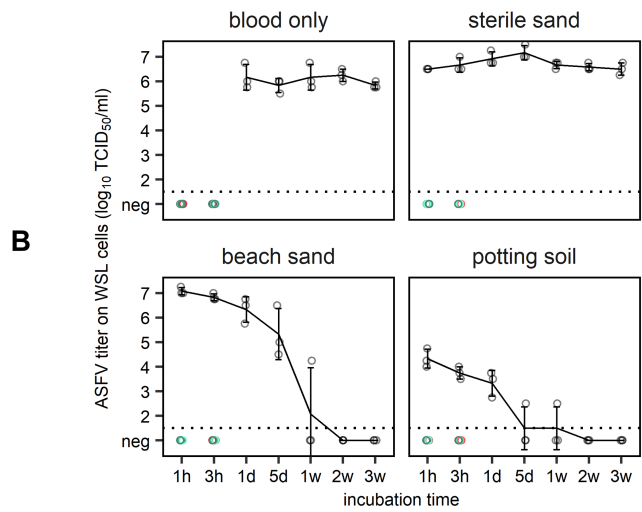

- no disinfectant

- calcium hydroxide $(7.0 \%)$

citric acid $(3.5 \%)$
$\circ$ citric acid $(7.0 \%)$
- no disinfectant

calcium hydroxide $(3.5 \%)$

citric acid $(3.5 \%)$
citric acid $(7.0 \%)$ 